\title{
Filtering the piotroski portfolio: the roles of economic sector, small cap, and technical momentum
}

\author{
Roy Rada \\ Department of Information Systems, University of Maryland Baltimore County, Baltimore, Maryland, 21250, USA \\ E-mail: rada@umbc.edu
}

\begin{abstract}
Background and Objective: In one of the most cited, value-investing results, a portfolio of approximately 100 stocks is selected based on value and fundamental factors. If an investor wants to select 10 of those recommended stocks, then to what extent might economic sector diversification, market capitalization, and technical momentum indicators be useful?

Method and Results: In this paper, several strategies produce the 10 -stock portfolio that retains the performance of the 100 -stock portfolio. Choosing the smallest market cap stocks tends to make the greatest, positive difference in gains, but deeper investigation reveals that those stocks may not be practically accessible investment vehicles.
\end{abstract}

Keywords: Portfolio Management; Value Investing; Fundamentals; Small Market Capitalization; Economic Sectors; Technical Momentum; RiskAdjusted Returns.

\section{Introduction}

The Piotroski method (Piotroski, 2000) when applied to the Compustat North America database generates a portfolio each year. Piotrowski's method of selecting stock to buy when applied to the universe of Compustat North America stocks might typically select approximately one hundred stocks each year. The average stock investor holds only a handful of stocks in his portfolio (Gerhardt \& Meyer, 2013; Goetzmann \& Kumar, 2008) and is heavily influenced by behavioral biases (Mouna \& Anis, 2015). With mean-variance portfolio theory, one can show that an optimal portfolio needs about 30 stocks (Statman, 1987). If a private investor wants to semi-automatically reduce the number of stocks recommended by the Piotroski method to approximately ten stocks, then how might further fundamental or technical rubrics help?

For decades, researchers have been identifying accounting anomalies and the ability to predict excess stock returns by exploiting those anomalies (Richardson, Tuna, \& Wysocki, 2010). That research shows that investors make false assumptions about companies with extreme book-to-market (BM) values (Chan \& Lakonishok, 2004). Piotrowski (2000) selects high BM stocks to earn above-average returns. Accruals are also useful in studying performance of a company (Jemaa, Toukabri, \& Jilani, 2015) Sloan (1996) shows that stock prices do not adequately reflect extraordinary items in the accruals.

Many value investing strategies exist. Greenblatt (2006) simplifies the Piotroski approach and uses only two factors. High BM stocks are 'value' stocks because they are deemed to be undervalued relative to their assets, while low BM stocks are 'growth' stocks. Mohanram (2005) screens for low BM stocks and then does a financial strength analysis based on quarterly financial statements but uses different factors than Piotroski used. While Piotroski finds one formula works for high BM stocks, and Mohanram finds an other formula works for low BM stocks, Beneish et al (2001) argue that given a category of stocks, a unique formula might best predict how stocks in that category will perform.

A portfolio should contain stocks whose covariance in stock price is negative (J. K. Lee, Trippi, Chu, \& Kim, 1990). One naive way to get this covariance is to assume that different economic sectors will perform differently (Cavaglia, Brightman, \& Aked, 2000; Hauser \& Vermeersch, 2002), although studies show the rubric is a weak one (Hauser \& Vermeersch, 2002; W. Lee, 2011). One of the hypotheses of this paper is that taking a subset of the Piotroski Portfolio based on diversification by economic sector will produce a return comparable to that of the entire set by getting appropriate diversification.

Piotrowski (2000) shows that small-cap stocks perform better than large-cap stocks. That small-cap stocks would perform well has been widely recognized, though the reasons for this phenomenon are sometimes disputed (Fama \& French, 1992). The size effect occurs across the world and across large periods of time but is also susceptible to experimental errors in its measurement (Dijk, 2011). In this paper, I will identify several filters to impose on the Piotroski Portfolio and then experiment with these filters. The filters include ones that aim for sector diversity, for small-capitalization stocks, and for technical momentum. However, these filters on the Piotroski Portfolio prove to not have a statistically significant impact on the performance of the resulting sub-portfolios. When the Piotroski Portfolio is widened in various ways, including ignoring the F-score, and the smallest market cap stocks are selected, then the portfolio performs remarkably well. I then show, however, that the performance of the very small-cap stocks is based on companies in precarious situations, such as ones filing for bankruptcy. Those companies almost stop trading before they resurrect themselves and make spectacular gains. Investors, however, might have difficulty investing in those stocks, although, as far as one can tell from Compustat, they remain tradable. 
The Piotroski Portfolio has been well documented to have certain performance. However, this author is not aware of published literature to show a systematic way to reduce the size of that portfolio and retain its performance. The academic contribution of this work is to show how the Piotroski Portfolio can be reduced in size and how that impacts the performance of the reduced portfolio. If one entirely removes the moderating influence of the F-score, then selecting from the undervalued stocks randomly or by economic sector significantly reduces performance, while choosing only the smallest market cap stocks is very risky. In other words, the Fscore is a valuable filter on undervalued stocks.

The size of the portfolio recommended in Piotroski's work is too large to be practically managed by a small, private investor. The practical contribution of this paper is to show how the individual investor can choose a small fraction of the stocks recommended by the Piotroski method without sacrificing performance. The filtering methods that produce the most dramatic, positive returns are shown to be too risky.

The remaining text is structured as Methods, Results, and Conclusion. Within the Method Section, I present what stock data was collected, how criteria for stock selection were computed, what portfolios were formed, and how the results of buying and selling stock are analyzed. The Results Section is organized primarily around four different ways of choosing the initial portfolio before filtering it. The first experiment uses the Piotroski Portfolio formed by computing the F-score and selecting stocks with Fscores over 7. The second experiment uses the entire universe of stocks as the initial portfolio, while the third experiment includes in the portfolio stocks whose F-score is 7, 8, or 9. The final experiment removes small-cap stocks from consideration. The Conclusion Section summarizes and interprets the work before suggesting future directions.

\section{Method}

This research involves collecting data on stocks, computing criteria, generating portfolios, and then analyzing the performance of those portfolios. Those four components of the method are described in the next four subsections.

\subsection{Data collection}

Standard \& Poor's is one of the premiere sources of financial, fundamental data for stocks. One of the products of Standard \& Poor's is called Compustat North America (S\&P, 2004) and is the product used for this study. In my first, data-collection step, the unique identifiers (GVKEY) of all active and inactive U.S.A. and Canadian stocks are retrieved. Next, for each stock, data is retrieved to indicate the month the accounting year ends; whether the company became inactive; and the economic sector (see Table $1)$.

Table 1: "Calendar, Deletion, and Sector"

\begin{tabular}{|l|l|}
\hline Acronym & Definition \\
\hline FYR & $\begin{array}{l}\text { The month-end for each company's accounting year. If the } \\
\text { FYR value was indicated as 'Not Available', then the stock } \\
\text { was removed from the data set. }\end{array}$ \\
\hline DLDTE & $\begin{array}{l}\text { The effective date (month and year) for deletion of an inac- } \\
\text { tive company. }\end{array}$ \\
\hline DLRSN & $\begin{array}{l}\text { The reason, such as acquisition, merger, or liquidation, of } \\
\text { an inactive company. }\end{array}$ \\
\hline GSECTOR & $\begin{array}{l}\text { The Economic Sector of the company from the 'Global } \\
\text { Industry Classification Standard' (GICS) code (Standard \& } \\
\text { Poor's, 2002). The GICS taxonomy indicates 9 economic } \\
\text { sectors, but also has a 'not assigned' category. For this work, } \\
\text { the GICS 'not assigned' category was considered a 'sector' } \\
\text { and thus the data set has effectively 10 economic sectors. }\end{array}$ \\
\hline
\end{tabular}

The Compustat North America database has attributes whose name is indicated in the leftmost column. What the name means and how it is used in this stock analysis project is described in the rightmost column.
For each GVKEY, annual values are collected for each year from 1993 to 2011 for two particular attributes called MKVALF and MKBKF. MKVALF represents the company's market value as of the company's fiscal year end. MKBKF is Price-to-Book Ratio which Compustat computes as MKVALF divided by Common Equity. MKBKF is inversely proportional to the Book-to-Market value that Piotroski uses as his primary filter.

Since I need to compute the effectiveness of a strategy for buying stocks based on past data, holding the stocks one year, and selling them, I need, at least, two consecutive years of financial data for a company before anything useful can be done with the stock data. The time-series data for MKBKF is screened, and any companies that do not have, at least, two consecutive years of MKBKF values are removed from the data set. The original set of unique GVKEYs has a cardinality of 31,613 . After removal of entries with no FYR and ones without two consecutive MKBKF values, the cardinality is lowered to 14,057 .

\subsection{Computed criteria}

For each year, I select active stocks in that year's lower quintile of MKBKF values. Next, I compute the F-score and several other values for those undervalued stocks. The F-score is designed to measure the overall quality of the firm's financial position.

The F-score is the sum of 9 binary signals or factors. Those 9 factors are Return on Assets (ROA), Cash Flow from Operations (CFO), Delta Leverage, Delta Liquidity, Delta Margin, Delta Turnover, Delta ROA, Equity Offering, and Accrual (see Table 2). Since each factor evaluates to either 1 or 0 for any given stock at any given year, the F-score ranges from 0 to 9.

Table 2: "F Factors"

\begin{tabular}{|c|c|}
\hline Factor Name & When Factor Value is 1 \\
\hline ROA & ROA $t>0$ \\
\hline $\mathrm{CFO}$ & CFO $t>0$ \\
\hline Delta Leverage & $\begin{array}{l}\text { (Long Term Debt } \mathrm{t} / \text { Total Assets } \mathrm{t})< \\
(\text { Long Term Debt }(\mathrm{t}-1) / \text { Total Assets }(\mathrm{t}-1))\end{array}$ \\
\hline Delta Liquidity & $\begin{array}{l}\text { (Total Current Assets t/Total Current Liabilities t) }> \\
\text { (Total Current Assets (t-1)/Total Current Liabilities (t- } \\
\text { 1) ) }\end{array}$ \\
\hline Delta Margin & $\begin{array}{l}((\text { Sales } t-\text { Costs of Goods Sold } t) / \text { Total Assets } t)> \\
((\text { Sales }(\mathrm{t}-1)-\text { Cost of Goods Sold }(\mathrm{t}-1)) / \text { Total Assets } \\
(\mathrm{t}-1))\end{array}$ \\
\hline Delta Turnover & $\begin{array}{l}(\text { Sales t/Total Assets t) }> \\
(\text { Sales }(\mathrm{t}-1) / \text { Total Assets }(\mathrm{t}-1))\end{array}$ \\
\hline Delta ROA & ROA t $>$ ROA t-1 \\
\hline Equity Offering & Shares Outstanding $\mathrm{t}<$ Shares Outstanding $\mathrm{t}-1$ \\
\hline Accrual & $\mathrm{CFO} \mathrm{t}>\mathrm{ROA} \mathrm{t}$ \\
\hline
\end{tabular}

Each factor is a binary signal which can have a value of 0 or 1 . The table shows the criterion that must be satisfied for the factor to have a value of 1 . If the factor does not meet the criterion, then the value is 0 .

In addition to the F-score and to incorporate technical data in the decision-making, I compute a 'technical signal'. For this computation, I first collect the monthly closing price and monthly total volume for the six months prior to the sell month. A 6-month momentum value is computed which is 1 if the average change in price*volume is positive and zero if the average change in price*volume is negative. The 3 -month momentum is similarly computed, and if the 3-month momentum is greater than the 6month momentum, then the technical indicator is incremented by 1. Accordingly, the possible values of the technical signal are 2,1 , or 0 .

Three other values are determined for each stock: possible buy price, sell price, and proportional gain. Proportional gain is the (sell price + annual dividends)/(buy price). The buy and sell price are explained next.

The price at which the stock would be purchased is determined by going five months forward from the fiscal year end month for the stock. The rationale here is that public dissemination of the annual report would have occurred within five months of the fiscal year 
end (the same strategy as used by Piotroski). This is the 'possible buy price'.

The price at which the stock would be sold is the price 12 months after the buy price was set. If no price is available in this 12th month, then I check whether a deletion date exists between the time the stock was bought and this 12th month.

If the stock is deleted, then the reason for the deletion is determined. If the reason for the deletion is bankruptcy, then the sale price is zero. If the deletion reason is a privatization, then the most current price between the time of deletion, and the time of purchase is used.

\subsection{Portfolios}

With the collected and processed data, I am ready to form portfolios. The methodology behind four different portfolio generation experiments will be described. For each year from 1993 to 2009 , portfolios were formed, held for a year, and then sold. Thus 17 years are covered.

In the first experiment, called Piotroski Filter, the following portfolios are generated as subsets of the Piotroski Portfolio:

- Random: Ten stocks are randomly chosen.

- Economic Sector (Sect): One stock from each of the 10 Economic Sectors is randomly chosen.

- Economic Sector followed by Low Market Cap (Sect Mkval): From the stocks in an Economic Sector the stock with lowest market capitalization is chosen.

- Economic Sector followed by Technical Momentum followed by Low Market Cap (Sect Tech Mkval): From the stocks in an Economic Sector, the stocks with the highest technical indicator values are chosen, and from those, the one with the lowest market cap is chosen.

- Smallest Market Cap (Mkval): The 10 smallest market cap stocks are chosen.

Since the market cap makes the biggest difference in the 'Piotroski Filter' experiments, in the second experiment the F-score of Piotroski is ignored. In that second experiment, the following portfolios are generated:

- No F-Score: From the lowest quintile of price-to-book stocks, the lowest quintile of market cap stocks is selected. This constitutes the 'No F-Score' Portfolio.

- Random: 10 stocks are randomly selected from the No FScore Portfolio.

- Sect: From the No F-Score portfolio, one stock from each economic sector is randomly selected.

- Mkval: The 10 lowest market cap stocks are selected from the No F-Score portfolio.

To find a compromise between the first and second experiments, the third experiment generates these portfolios:

- Widen the Net: The F-score could be 7, 8, or 9 (whereas in the Piotroski case, the F-score had to be 8 or 9).

- Sect: For each economic sector randomly choose one stock from the 'Widen the Net' Portfolio.

- Sect Mkval: From each economic sector in the 'Widen the Net' Portfolio, a stock in the lowest market cap quintile is selected.

- Mkval Tech: Stocks in the lowest market cap quintile are chosen from 'Widen the Net'. Then stocks with the highest technical momentum factor are chosen.

Finally, the first experiment is repeated except that the lowest quintile of market cap stocks is removed from consideration.

\subsection{Results Analysis}

The results are primarily analyzed by computing a geometrical mean and then doing a bootstrap statistical analysis of the geometrical mean data. For the geometrical mean, first the average proportional gain of all the stocks in a portfolio in a year is computed. Next the geometrical mean of the 17 years of proportional gains is computed (Jacquier, Kane, \& Marcus, 2003). The proportional gains are not normally distributed, and a well-accepted approach to testing for statistical significance with populations such as these is the bootstrap approach (which is what Piotroski used). The method of implementing the bootstrap follows:

1) Given Portfolio $X$ with cardinality ${ }_{x}$ a sample is drawn with replacement from Portfolio $X$ to create a Portfolio X' of cardinality $_{\mathrm{x}}$. The mean proportional gain of Portfolio $\mathrm{X}^{\prime}$ is computed. Likewise, given a Benchmark Portfolio with cardinali$t_{\text {benchmark }}$ a sample is drawn with replacement from the Benchmark Portfolio to create a Benchmark Portfolio' with cardinality $y_{\text {benchmark }}$ and its mean proportional return is computed.

2) The difference between the two means is computed and stored.

3) The first two steps are repeated 1,000 times.

4) The set of 1,000 mean values are sorted and the values at positions $25,50,950$, and 975 determine the confidence intervals.

If the hypothesis is that the mean proportional gain for Portfolio $\mathrm{X}$ is larger than the mean portfolio gain for the Benchmark Portfolio, then the values at positions 50, 950, and 975 must all be positive. If the hypothesis is that the means of the two populations are different, then all four positions must have the same sign.

To get a better descriptive sense of what is happening with the data, I compute both the standard deviation and the risk-adjusted returns. All the stocks in a portfolio type across the 17 years are put together into one set, and the standard deviation in the set is computed. To get the risk-adjusted returns, first the Sharpe Ratio of (Proportional Gain of Portfolio X - Proportional Gain of Benchmark Portfolio)/ (Standard Deviation of Difference between the two Portfolios) is computed. Then the Modigliani risk-adjusted return (Modigliani \& Modigliani, 1997) is computed as the Sharpe Ratio times the 'Standard Deviation of the Benchmark Portfolio'.

Since the portfolios prove to have widely varying returns, I look deeply into some of the outlier stocks that were selected. While Compustat provides a wealth of data about each stock, that data is highly codified into certain database fields. Some important features about a stock are further obtained by reading in detail elsewhere about the stock history.

The preceding approach of grouping data across multiple years is consistent with what Piotroski did (Piotroski, 2000). An interesting further analysis would compute the proportional gain on the entire universe of North American stocks and compare that to the selected subsets. However, the goal of the research here is restricted to looking at portfolios formed from undervalued stocks. In the Results Section, I note the proportional gain of the S\&P 500 and compare that to the gains on the portfolios I generate.

\section{Results}

The results are presented next in four subsections, one per experiment, and titled 'Piotroski Filter', 'No F-score', 'Widen the Net', and 'Without Small Caps'. For each experiment, the geometric means and the bootstrap, statistical significances of those means are first presented. Then the standard deviation and risk-adjusted return are noted before the importance of individual top gainers is illustrated. As a baseline, the reader should take note of the returns of the S\&P 500 Indexes which for the 17 years of this study had a geometric mean of proportional gains of 1.08 , which is much less than the gains of the portfolios shown next.

\subsection{Piotroski filter}

The different portfolios for the Piotroski Filter experiment are explained in the Methods Section. Here the performance results of these portfolios are summarized. In this and subsequent descriptions,

- Economic Sector is shortened to Sector,

- Economic Sector followed by Small Market Capitalization is shortened to Sector Mkval, 
- Economic Sector followed by Technical Momentum followed by Small Market Capitalization is shortened to Sector Tech Mkval, and.

- Small Market Capitalization is shortened to Mkval.

The portfolios chosen randomly or by economic sector have the smallest geometrical means (see Table 3). The highest geometrical mean is for the method that simply took the smallest market cap stocks from the Piotroski Portfolio. The standard deviations of the higher performing portfolios are larger than the standard deviation of the Piotroski Portfolio and are largely correlated with the geometric means. In other words, when return is greater, the risk is greater. A bootstrap analysis shows that the data do not have significantly different means. The distribution of mean differences is almost entirely positive for the portfolios involving market cap; however, the differences are not statistically significant. The 'Mkval' portfolio has the highest risk-adjusted return.

Table 3: Descriptive Statistics and Significance for the Basic Filtering Experiment

\begin{tabular}{|c|c|c|c|c|c|c|c|}
\hline \multirow[t]{2}{*}{ Portfolio } & \multirow{2}{*}{$\begin{array}{r}\text { Geo } \\
\text { Mean }\end{array}$} & \multirow{2}{*}{$\begin{array}{r}\text { St } \\
\text { Dev }\end{array}$} & \multirow{2}{*}{$\begin{array}{r}\text { Risk } \\
\text { Adj }\end{array}$} & \multicolumn{4}{|c|}{$\begin{array}{c}\text { Means per } \\
\text { confidence threshold }\end{array}$} \\
\hline & & & & .025 & .05 & .95 & .975 \\
\hline Piotroski & 1.27 & 2.83 & & & & & \\
\hline Random & 1.17 & .80 & -.12 & -.36 & -.31 & .05 & .07 \\
\hline Sector & 1.22 & .92 & -.06 & -.28 & -.23 & .11 & .14 \\
\hline $\begin{array}{l}\text { Sector } \\
\text { Mkval }\end{array}$ & 1.53 & 7.43 & .14 & -.07 & -.03 & 1.75 & 2.08 \\
\hline $\begin{array}{l}\text { Sector } \\
\text { Tech } \\
\text { Mkval }\end{array}$ & 1.57 & 7.37 & .14 & -.08 & -.04 & 1.73 & 1.94 \\
\hline Mkval & 1.59 & 7.26 & 16 & -.08 & -.02 & 1.87 & 2.19 \\
\hline
\end{tabular}

'Geo Mean' is 'Geometric Mean', 'St Dev' is 'Standard Deviation', and 'Risk Adj' is 'Risk-Adjusted Return'. The risk-adjusted return is per (Modiglian \& Modigliani, 1997) as described in the Methods Section. The rightmost four columns contain the values elaborated in the Methodology Section about the bootstrap analysis; in brief, those four columns are the extreme differences in return means between the randomly generated portfolio and the original portfolio.

Given the striking patterns of variability in the data, I study the individual stocks. The Piotroski Portfolio has 1,178 stocks in it over the 17 years, while the other portfolios each have 170 stocks in them. The top 5 earners show a strong skew pattern (see Table 4). The Portfolios that surpass the Piotroski Portfolio in performance all have the same, two highest earners (which have proportional gains of 90 and 30).

Table 4: Top 5 Individual Winnings for the Piotroski Filter Experiment

\begin{tabular}{|r|r|r|r|r|r|}
\hline Piotroski & Random & Sector & $\begin{array}{r}\text { Sector } \\
\text { Mkval }\end{array}$ & $\begin{array}{r}\text { Sector Tech } \\
\text { Mkval }\end{array}$ & Mkval \\
\hline 90.00 & 8.30 & 8.50 & 90.00 & 90.00 & 90.00 \\
\hline 30.00 & 3.20 & 4.14 & 30.00 & 30.00 & 30.00 \\
\hline 8.50 & 3.14 & 4.05 & 8.50 & 4.05 & 8.50 \\
\hline 8.50 & 3.02 & 3.92 & 8.50 & 3.92 & 8.50 \\
\hline 8.30 & 2.80 & 3.83 & 6.50 & 3.83 & 6.50 \\
\hline
\end{tabular}

The portfolio name is given in the first row. In the other rows, per portfolio the proportional gain of the 5 stocks with the largest proportional gain are shown in descending order. As defined in the Methods Section, the proportional gain is the (sell price + annual dividends)/ (buy price).

The descriptive statistics are compelling for the importance of capturing the stock that has a proportional gain of 90 in the portfolio. What else might one want to know about that stock? It is the same company in each portfolio, and that company is in bankruptcy proceedings when the stock is purchased.

\subsection{No F-score}

What if I only choose the lowest market cap firms and do not use F-Scores. In this experiment, as explained in the Methods Section, the base portfolio each year has all stocks in the lowest quintile price-to-book. Subsequently, 10-stock subsets are chosen from that large set either randomly, based on economic sector, or based on the lowest market cap.

The geometrical means of the 17-year performance by portfolio show a rapid rise from 0.86 to 1.18 to 2.78 for the Random, Economic Sector, and Market Cap portfolios, respectively (see Table 5). The 'No F-Score' Portfolio has a geometrical mean of 1.65 , which is larger than the Piotroski Portfolio whose geometric mean was 1.27 .

The results for the 'No F-Score' portfolios are statistically significant (see Table 6 "No F-Score"). The mean of returns for the Random, and the Economic Sector portfolios are significantly lower than the 'No F-Score' means. However, the portfolio containing yearly the 10 lowest market cap stocks has a significantly higher mean return.

Table 5: Descriptive Statistics and Significance for the No F-Score Experiment

\begin{tabular}{|c|c|c|c|c|c|c|c|}
\hline \multirow{2}{*}{ Portfolio } & \multirow{2}{*}{ Geo } & \multirow{2}{*}{$\begin{array}{l}\text { St } \\
\text { Dev }\end{array}$} & \multirow{2}{*}{$\begin{array}{l}\text { Risk } \\
\text { Adj }\end{array}$} & \multicolumn{4}{|c|}{ Means per confidence threshold } \\
\hline & & & & 0.025 & 0.05 & 0.95 & .975 \\
\hline $\begin{array}{l}\text { No F- } \\
\text { Score }\end{array}$ & 1.65 & 43.34 & & & & & \\
\hline Random & 0.86 & 0.91 & -3.78 & -1.69 & -1.61 & -.62 & $\overrightarrow{-.56}$ \\
\hline Sector & 1.18 & 1.47 & -1.70 & -1.34 & -1.25 & -.21 & -.14 \\
\hline Mkval & 2.78 & 139.7 & $\overline{50}$ & .57 & .98 & 36.4 & 40.5 \\
\hline $\begin{array}{l}\text { 'Geo' is ' } \\
\text { is 'Risk- } \\
\text { return is } \\
\text { indicate t }\end{array}$ & eriri & $\begin{array}{l}\text { an', 'St } \\
\text { n'. Th } \\
\text { e Met } \\
\text { essary }\end{array}$ & is 'S & $\operatorname{lard~I}$ & $\begin{array}{l}\text { iation', } \\
\text { g the ris } \\
\text { tmost } \mathrm{f} \\
\text { lysis. }\end{array}$ & $\begin{array}{l}\text { d 'Ris } \\
\text { adjust } \\
\text { r colu }\end{array}$ & \\
\hline
\end{tabular}

The standard deviations from these portfolios show marked differences (see Table 5). The standard deviation of the base portfolio is 43 , of the random portfolio is 1 , and of the lowest market cap, portfolio is 140 . The lower market cap stocks are cause for major variability in performance. The large variation in the lowest small cap portfolio has reduced the risk-adjusted return substantially to 0.50 .

The top five proportional gainers in each portfolio show the extremely high returns of some stock (see Table 6). The union of the 17 years of 'No F-Score' Portfolios has 21,839 entries, while each of the other three portfolios has 170 stocks. The stock with the highest market return in the filtered portfolios had a proportional gain of 1,375. How realistic is it that an investor might have earned that return? I buy the stock in the 5th month of 2004. However, in the entire 5th month of 2004, Compustat notes that only 1,350 shares of this company trade.

Table 6: Top 5 Individual Winnings for the No F-Score Experiment

\begin{tabular}{|r|r|r|r|}
\hline \multirow{2}{*}{ No F-Score } & \multicolumn{3}{|c|}{ Filtered by } \\
\cline { 2 - 4 } & Sector & Mkval & Random \\
\hline 4,500 & 10 & 1,375 & 8 \\
\hline 3,300 & 10 & 1,200 & 6 \\
\hline 1,708 & 8 & 107 & 3 \\
\hline 1,375 & 8 & 80 & 3 \\
\hline 1,333 & 7 & 70 & 3 \\
\hline
\end{tabular}

The portfolio name is given in the top 2 rows. In the bottom 5 rows, the proportional gain of the top 5 stock market earners in each portfolio are shown in descending order.

\subsection{Widen the Net}

In this experiment, the net is widened in that the F-Score only needs to be greater than 6 rather than greater than 7 in order for a stock to be included in this 'Widen the Net' Portfolio. The rationale here is that the filtering of the 'Widen the Net' Portfolio might lead to stronger results, since that filtering will have more stocks from which to choose. In the previous results, the technical indicator helps filter the small cap winners from losers. Accordingly, a portfolio is created that selects the lowest quintile market cap stocks from the 'Widen the Net' Portfolio and then selects from that subset the 10 stocks that have the highest technical momentum (the Mkval Tech Portfolio). The hypothesis is that the 
filtered subsets will perform better than the 'Widen the Net' Portfolio.

The Sector Mkval Portfolio has a geometrical mean of proportional gains over 17 years of 1.42. The Mkval Tech Portfolio had a geometrical mean of 1.86 (see Table 7). Given that the 'Widen the Net' Portfolio has a geometric mean of 1.28, those two filtered subsets bring a big improvement.

Table 7: Descriptive Statistics and Significance for the 'Widen the Net' Experiment

\begin{tabular}{|c|c|c|c|c|c|c|c|}
\hline \multirow{2}{*}{ Portfolio } & \multirow{2}{*}{ Geo } & \multirow{2}{*}{$\begin{array}{l}\text { St } \\
\text { Dev }\end{array}$} & \multirow{2}{*}{$\begin{array}{l}\text { Risk } \\
\text { Adj }\end{array}$} & \multicolumn{4}{|c|}{ Means per confidence threshold } \\
\hline & & & & 0.025 & 0.05 & 0.95 & 0.975 \\
\hline $\begin{array}{l}\text { Widen the } \\
\text { Net }\end{array}$ & 1.28 & 2.18 & & & & & \\
\hline Sector & 1.28 & 1.17 & .00 & -.20 & -.17 & .16 & .19 \\
\hline Sector Mkval & 1.42 & 2.14 & .11 & -.02 & .02 & .57 & .63 \\
\hline Mkval Tech & 1.86 & 7.64 & .18 & .23 & .32 & 2.21 & 2.55 \\
\hline Portfolios are & ie lef & sst c & & & tric & ean', & $\begin{array}{l}\text { ev' is } \\
\text { right- } \\
\text { lysis. }\end{array}$ \\
\hline
\end{tabular}

The riskiness of the portfolios also increases with the geometric means (see Table 7). Despite the increasing variability as the returns increased, the risk-adjusted returns still show a major gain by using the appropriate filtering. The Mkval Tech Portfolio has a risk-adjusted return of 0.18 .

The test of statistical significance of the bootstrap technique shows at the 0.05 confidence level that both Sector Mkval and Mkval Tech Portfolios perform significantly better than the 'Widen the Net' Portfolio (see Table 7).

The top 5 gainers in each portfolio show that the highest gaining portfolio (the Mkval Tech) has picked the same best winners as the large 'Widen the Net' Portfolio, but since the Mkval Tech Portfolio is much smaller, those winners have a much larger effect on the final returns. In both the 'Widen the Net' and the 'Mkval Tech' Portfolios, the top 2 gainers have a proportional return of 90 and 30, as they did in the 'Piotroski Filter' experiment.

\subsection{Without small caps}

The lowest market cap stocks have the highest volatility and investing appropriately in them gives the highest possible gain. At the same time, investing in them appropriately can be very difficult for most investors. Accordingly, one might wonder what would happen to the filtering strategies were they to be applied to stocks that excluded the lowest quintile market cap stocks. In this final experiment, each year the viable stocks are first divided into their market cap quintiles, and the lowest quintile became ineligible to be selected for any portfolio. The various further filters are as described in the Methods Section.

The geometrical means of the 17-year returns for the new portfolios are much reduced over those in the experiments that used the lowest quintile of market cap stocks (see Table 8). The 'Without Small Caps' Portfolio, geometrical mean has reduced to 1.19 , and the non-random filters earn a return between 1.18 and 1.23 -- very different from the geometric means generated with the smallest market cap stocks in the portfolios. Piotroski has a similar result and gets about $25 \%$ return with small-cap stocks and $15 \%$ return with large-cap stocks.

Table 8: "Returns without Small Caps"

\begin{tabular}{|l|r|r|r|}
\hline Portfolio & $\begin{array}{r}\text { Geometric } \\
\text { Mean }\end{array}$ & $\begin{array}{r}\text { Standard } \\
\text { Deviation }\end{array}$ & $\begin{array}{r}\text { Risk-adjusted } \\
\text { Return }\end{array}$ \\
\hline Without Small Caps & 1.19 & 0.92 & \\
\hline Random & 1.14 & 0.79 & -.03 \\
\hline Sector & 1.18 & 0.78 & -.01 \\
\hline Sector Mkval & 1.23 & 0.84 & .05 \\
\hline Sector Tech Mkval & 1.21 & 0.73 & .03 \\
\hline
\end{tabular}

In this table, the portfolio labels are in the leftmost column and the descriptive statistics in the remaining 3 columns.

When all the data across the years of a given portfolio style are clumped together, and the standard deviations of the proportional gains are computed, the variability is much less in this experiment. The risk-adjusted return for the Random and Sector Portfolios is a small negative number, while the risk-adjusted return is a small positive number for the other filtered portfolios. The bootstrap analysis shows that the means of the various portfolios when compared to that of the Piotroski Portfolio are not significantly different.

The top five gainers in each of the portfolios tell the story in another way. The 'Without Small Caps' Portfolio has 2,118 stocks in it, but the stock with the best gains had a proportional gain of 20 . For the filtered portfolios, no stock has a proportional gain as high as 7. Removing the lowest quintile of market cap stocks from consideration has a radical impact on the distribution of gains within the portfolio and left a far less risky but also less lucrative result.

\subsection{Fama-French model}

High value or low market cap stocks tend to have higher earnings (Fama, French 1992; Carhart 1997). To what extent are the results of this paper modeled by the Fama-French 3 -factor model? The factors of the Fama-French 3 factor model are Market Return, 'Small Minus Big market capitalization' (SMB), and 'High Minus Low value' (HML) and are computed based on all stocks listed on the major American markets.

I re-examine the portfolios of this study and compute the monthly proportional change in value of each holding in the portfolio before computing the monthly proportional change in the portfolio. I create a table in Microsoft Excel where the rows are the months my portfolios were held, and the columns are Portfolio Excess Return, Market Excess Return, SMB, and HML. Finally, the Portfolio Excess Return is regressed against the Market Excess Return, SMB, and HML.

Excel provides an F-statistic for the ratio of the mean square regression to the mean square residual. This statistic is compared with the critical $F$ value to test the null hypothesis with a $p$ below 0.05 indicating a rejection of the null hypothesis. The FamaFrench 3-factor model does not well model the portfolios studied here. Across the many portfolios, almost no regression is statistically significant.

\section{Conclusion}

This work shows that the Piotroski method published in 2000 when applied to the Compustat North America database for the years 1993 to 2011 continues to show results as it did for the older data that Piotroski studied. The results on the various filter strategies are surprising and are summarized next.

The Piotroski method (with the F-Score greater than 7) when applied to the Compustat North America database generates on the order of 100 stock picks per year. The hypothesis that arbitrarily selecting one stock from each economic sector would raise the profitability of the portfolio has been shown to be false. Picking the smallest market cap stock in each economic sector leads to a jump in earnings but not a statistically significant jump. A technical momentum filter does not help. Ignoring the economic sectors and simply picking the 10 lowest market cap stocks also does not produce a statistically significant result. However, all the methods of picking stock from the Piotroski Portfolio, other than the random method, either maintain or increase the profitability. Noteworthy is the positive impact of the small cap filter on profitability.

To see how far one could go with the small-cap stocks, F-score is ignored, and I simply take undervalued stocks with low market capitalization and then filter those stocks with the aforementioned techniques. The 'No F-Score' Portfolio is typically twenty times the size of the Piotroski Portfolio. Picking the 10 lowest market cap stocks from the 'No F-Score' Portfolio produces statistically significantly higher returns. Applying a technical momentum filter to the small-cap stocks further improves profitability. One of the 
stocks evidences a 1,375 fold increase in value. However, closer examination reveals that an investor might have been hard-pressed to successfully buy a substantial number of shares at the quoted price. These small-cap stocks are very thinly traded and investing in them might not be consistently practical.

Returning to the Piotroski Portfolio method but enlarging the set of stocks from which to apply the filtering might allow for statistically significant results. To increase the size of the Piotroski Portfolio the F-Score is allowed to dip to 7 to create a new portfolio called 'Widen the Net'. The geometric mean of the 'Widen the Net' Portfolio remains the same as it was for the Piotroski Portfolio with the F-Score greater than 7. This does, however, roughly double the size of the Piotroski Portfolio. Now the results with small cap and technical momentum filters are statistically significant and show that picking very low market cap stocks increase the profitability, and from low cap stocks, picking those with positive technical momentum improves performance further. The problem remains, however, that very few stocks are skewing the results, and in practice, those stocks might lack liquidity.

Mid- and large-cap stocks tend to be liquid. An experiment was done in which the lowest quintile, market cap stocks are removed from further consideration to produce the 'Without Small Caps' Portfolio. Repeating the Piotroski method on this pruned universe leads to lower returns but still better than the S\&P 500 Indexes. The various filters for reducing the size of the 'Without Small Caps' Portfolio have no statistically significant impact on performance.

In review, a filter by economic sector does not significantly increase or reduce return. Choosing small-cap stocks leads to enormous gains. A technical momentum indicator supports the selection of winners from losers among these high-risk small-cap stocks. However, the method here does not account for potential illiquidity.

These semi-automated methods of picking portfolios are misleadingly productive for small-cap stocks because the highest performing stocks may be inaccessible to the average investor. Instead, professional investors might work with such a semi-automated screen and add further techniques to determine which small-cap stocks were practical investment vehicles. On the other hand, this work has shown how the Piotroski Portfolio can be successfully reduced in size without significantly impacting performance.

In the data already analyzed, a statistically significant result tends to depend on a few, anomalous stock returns. That dependence on a few stocks suggests that returns in a given year might be much better than the market index return but that in some other years would be worse than the market index. Further analysis might look at each year separately.

Piotroski requires a stock's trading volume to exceed a certain daily threshold before he included that stock in a portfolio. I do not use such a pre-processing filter, and my stocks might at times trade very thinly. An extension of my experiment might include trading volume data.

The presented work answers certain investing questions with simulations on Compustat's North America database. The answers could be useful to an academic or a practitioner interested in buying undervalued stocks with strong fundaments, while maintaining only a small portfolio.

\section{Acknowledgements}

The author wishes to thank his former Ph.D. students, Dr. Jie Du and Dr. Hayden Wimmer, for discussions about semi-automated stock investing.

\section{References}

[1] Cavaglia, S., Brightman, C., \& Aked, M. (2000). The Increasing Importance of Industry Factors. Financial Analysts Journal, 41-54. http://dx.doi.org/10.2469/faj.v56.n5.2389.
[2] Chan, L. K., \& Lakonishok, J. (2004). Value and growth investing: Review and update. Financial Analysts Journal, 60(1), 71-86. http://dx.doi.org/10.2469/faj.v60.n1.2593.

[3] Dijk, M. A. v. (2011). Is size dead? A review of the size effect in equity returns. Journal of Banking and Finance, 35(3263-3274). http://dx.doi.org/10.1016/j.jbankfin.2011.05.009.

[4] Fama, E. F., \& French, K. R. (1992). The cross-section of expected stock returns. Journal of Finance, 54, 427-465. http://dx.doi.org/10.1111/j.1540-6261.1992.tb04398.x.

[5] Gerhardt, R., \& Meyer, S. (2013). The effect of personal portfolio reporting on private investors. Financial Markets and Portfolio Management, 27(3), 257-273. http://dx.doi.org/10.1007/s11408-013-02149.

[6] Goetzmann, W. N., \& Kumar, A. (2008). Equity Portfolio Diversification. Review of Finance, 12, 433-463. http://dx.doi.org/10.1093/rof/rfn005.

[7] Greenblatt, J. (2006). The Little Book That Beats the Market. Hoboken New Jersey: John Wiley \& Sons.

[8] Hauser, T., \& Vermeersch, D. (2002). Is Country Diversification still better than Sector Diversification? Financial Markets and Portfolio Managment, 16(2), 234-253. http://dx.doi.org/10.1007/s11408-0020206-7.

[9] Jacquier, E., Kane, A., \& Marcus, A. (2003). Geometric or Arithmetic Mean: A Reconsideration. Financial Analysts Journal, 59(6), 46-53. http://dx.doi.org/10.2469/faj.v59.n6.2574.

[10] Jemaa, O. B., Toukabri, M., \& Jilani, F. (2015). Accruals and the prediction of future operating cash-flows: evidence from Tunisian companies. International Journal of Accounting and Economics Studies, 3(1), 1-6.

[11]Lee, J. K., Trippi, R. R., Chu, S. C., \& Kim, H. S. (1990). K-FOLIO: Integrating the Markowitz model with a knowledge- based system. Journal of Portfolio Management, 17(1), 89-93. http://dx.doi.org/10.3905/jpm.1990.409299.

[12]Lee, W. (2011). Risk-Based Asset Allocation: A New Answer to an Old Question? Journal of Portfolio Management, 37(4), 11-28. http://dx.doi.org/10.3905/jpm.2011.37.4.011.

[13] Modigliani, F., \& Modigliani, L. (1997). Risk-Adjusted Performance: How to measure it and why. Journal of Portfolio Management, Winter 45-54. http://dx.doi.org/10.3905/jpm.23.2.45.

[14]Mohanram, P. (2005). Separating Winners from Losers among Low Book-to-Market Stocks Using Financial Statement Analysis. Review of Accounting Studies, 10, 133-170. http://dx.doi.org/10.1007/s11142$\underline{005-1526-4}$

[15] Mouna, A., \& Anis, J. (2015). A study on small investors' sentiment, financial literacy and stock returns: evidence for emerging market. International Journal of Accounting and Economics Studies, 3(1), 10-19. http://dx.doi.org/10.14419/ijaes.v3i1.4098.

[16] Piotroski, J. (2000). Value Investing: The Use of Historical Financial Statement Information to Separate Winners from Losers. Journal of Accounting Research, 38, 1-41. http://dx.doi.org/10.2307/2672906.

[17]Richardson, S., Tuna, I., \& Wysocki, P. (2010). Accounting anomalies and fundamental analysis: A review of recent research advances. Journal of Accounting and Economics, 50(2-3), 410-454. http://dx.doi.org/10.1016/j.jacceco.2010.09.008.

[18] S\&P. (2004). Research Insight North America Data Guide. Centennial Colorado: McGraw-Hill Standard \& Poor's.

[19]Statman, M. (1987). How Many Stocks Make a Diversified Portfolio? Journal of Financial and Quantitative Analysis, 22(3), 353-363. http://dx.doi.org/10.2307/2330969. 